\title{
PANDEMIC-PLUS: THE COVID-19 LOCKDOWN AND ITS CORRELATION WITH DOMESTIC VIOLENCE
}

\author{
Muhammad Danyal \\ University Gilani Law College, \\ Bahauddin Zakariya University, Multan \\ Khananyal@bzu.edu.pk \\ Ammara Mujtaba \\ Department of Business Administration, \\ Bahria University Islamabad \\ Ammara.buic@bahria.edu.pk
}

\begin{abstract}
The countrywide lockdown in Pakistan was enforced on the $1^{\text {st }}$ of April which lasted till the $9^{\text {th }}$ of May 2020. The Punjab Unified Communication and Response (PUCAR-15) statistical data indicates that a total of 25 percent rise was observed in the cases of domestic violence during the lockdown. Therefore, it is imperative to examine the evidence, reason, and corrective measures to limit and control the domestic violence against women in Pakistan. This paper analyzes the current literature, legal framework, and necessary preventive measures to tackle the issue of domestic violence to safeguard the women staying at home.
\end{abstract}

Keywords: COVID-19, Lockdown, Domestic Violence, Women rights, Pakistan

\section{INTRODUCTION}

Over the previous months, reports from several countries including Argentina, Brazil, India, Pakistan, and the United Kingdom, show an increase in femicides (female homicides). A study by ActionAid depicts a massive increase in cases of domestic violence in Italy $(+59 \%)$, Nigeria, Palestine $(+700 \%)$, and Bangladesh (+983\%) between March and April 2020 as opposed to the data from the same months in 2019 (Lundrin, 2020). In the United States, there have been reports of men who took steps to toss their spouses out when they were suspected to have been infected by the virus. Furthermore, the domestic violence tracker provides live documentation and records of the increase in aggressive behaviour against women and girls during the pandemic.

In general, it is women who are most vulnerable to experience the full economic effects of the pandemic. For instance, in Pakistan, women are more susceptible to violence and aggression from their partners and their families. Around the globe, women are also overrepresented in the informal sector without labour laws, protection, or approach to social security nets. Age presents itself as another target area of susceptibility. For example, in Belgium, one in three women above the age of 60 years gave an account of geriatric abuse, and as many as $67 \%$ of the sufferers live with their abuser (Lundrin, 2020). The violence reported by them spans economic and physical abuse - for example, tying up an accomplice experiencing dementia for their wellbeing - to mental brutality, including emotional blackmailing, mortification, burglary, or disregard.

Even in circumstances when the breaking point is reached, and a woman decides that she can no longer accept or deal with the harsh behaviour, it might not be possible for her to get access to the public assistance services. In addition to that, due to inaccessibility to phones or the internet, women living in distant areas have limited access to such facilities and information. Globally, the chances of women owning a phone are $10 \%$ less than me, and those who do are $23 \%$ less likely to have access to mobile internet. Women with an insecure legal status may not have the approachability to community services and if they do, they may be scared of the implications (Lundrin, 2020).

Ferocity against females is extremely pervasive and the most well-known type of brutality is close partner violence. During the Covid-19 crisis violence risk for children and females must not be disregarded. In the 1973 constitution $18^{\text {th }}$ Amendment authorized provinces, Sindh, Balochistan, and Punjab to have acquainted laws with empowering ladies and guarantee sex equality. During the year 
2013, the Sindh government authorized its Domestic Violence (Protection and Prevention). In 2014 Balochistan approved parallel law. Punjab has presented a couple of significant legitimate strides towards strengthening of women. These include the adoption of Punjab Protection of Women Against Violence Act, 2016, Punjab Protection of Women against Violence Act 2015, Punjab Commission on the Status of Women 2014, Punjab Protection of Women against Harassment at the Workplace Act 2012, and Punjab Women Protection Authority. Unfortunately, there is no law in Khyber Pakhtunkhwa right now to ensure overcomers of homegrown maltreatment "due to push back from religious authorities" in 2020 report says UNODC. The UNODC report shows that solitary 0.4 percent of ladies take their cases to courts and 50\% of ladies who experience abusive behavior at home do not react in any capacity (Khan, 2019).

In this study, using the available literature, as well as the secondary statistical studies, the paper finds the factors of the surge in domestic violence cases because of lockdown. The study aims at providing a systematic recommendation for the policymakers, awareness to the victims of domestic violence, and contributing to the existing literature.

\section{REVIEW OF LITRATURE}

During Covid-19 a developing stream of writing has featured that there is an expansion in abusive behavior domestic violence cases. Studies concentrating on the effect of philanthropic crises and cataclysmic events on aggressive behavior at home have indicated that the pressure-related to these crises prompts an expansion in violence against women (Bradbury-Jones, 2020). In the current setting of the COVID-19 pandemic, the repression measures may have enhanced this expanded danger of violence against women. The isolate and physical removing measures may have prompted an expansion in the seriousness and recurrence of accomplice savagery. In their ongoing examination, (Campbell, 2020) distinguish the dumbfounding impacts of a pandemic in this specific circumstance. An ongoing article from The Guardian gives an account of the flood in aggressive behavior at home and stresses an example that can be noticed all around the world. This incorporates an ascent of 40half in abusive behavior at home occurrences in Brazil, a spiking in calls to helplines in Spain and Cyprus by $20-30 \%$ inside the initial not many days of the imprisonment time frame and seven days after the primary Covid-19 patient was analyzed, and a $25 \%$ expansion in calls identified with abusive behavior at home cases in the UK inside seven days after exacting social separating and lockdown measures were enacted. 8 Regarding the impacts of Covid-19 on aggressive behavior at home in the USA, (Goyal, 2020) show that a few states have encountered a spike in cases, for instance, Portland encountering a $22 \%$ expansion in captures identified with aggressive behavior at home, Jefferson County Alabama encountering a 27\% expansion in aggressive behavior at home calls during March 2020 contrasted with March 2019, and during March 2020 contrasted with March 2019 New York City encountering a $10 \%$ expansion in aggressive behavior at domestic calls.

Besides, it has been seen that different examinations, either distributed in scholastic sources or during the time spent the turn of events, additionally show that Covid-19 is affecting aggressive behavior at the local level. Be that as it may, examining the effect of a pandemic or a pestilence on abusive behavior at the local level isn't new. For instance: (Jenkins, 2018) researched influence on female maltreatment potential HIV epidemic; (Lowery, 2019) (Schumacher, 2010) related basic viciousness and destitution to the AIDS pandemic; and (Smith, 2014) indicated how the US HIV pandemic prompted social inconveniences for various racial and sex gatherings, bringing about savagery. Also, like a pandemic, the impacts of cataclysmic events on aggressive behavior at home have been explored. (Straus M. a., 1992) remarked on abusive behavior at domestic happening after a debacle; (Jackson, 2020) announced that savagery against ladies increments in networks hit by ecological fiascos; (Straus M. a., 1992), with regards to Bangladesh, contended that overall impacts of catastrophic event and absence of medical services post-calamity make ladies powerless against conceptive and sexual medical problems and increment the episodes of home-grown and sexual viciousness; and (Kensbock S. J., 2013) in the range of 1999 and 2007 uncovered the effect of cataclysmic events on aggressive behavior at home utilizing an investigation of basic attack reports from Florida. Regardless of whether it is a pandemic or a cataclysmic event, abusive behavior at domestic rates are influenced. Be that as it may, there is restricted examination accessible uncovering 
the explanations for such impacts and, all the more significantly, how they come to impact normal financial and social emergency.

\section{THE CONTEXT OF DOMESTIC VIOLENCE IN PAKISTAN}

By male partners and torture and wildness by parents become a portion of the joint family framework. These types of cruelty get premise in different political, social, and financial components (Logar, 2017). Justifications are presented to 'approve' this brutality dependent on failed understandings of religious, norms, and social life. Beating spouses' violence puts an extraordinary physical and mental effect on wives. Besides Impacts the essential social establishment looking like family by carrying viciousness to the degree of torment and insensitive treatment of ladies (Basch, 2018) .In Pakistan, Husbands are commonly considered reserving the privilege to beat their spouses to keep them as per man-centric standards dependent on religious and social circle. The self-asserted idea of right gets interior legitimizations dependent on social practices, religious content. Also, outside coercive measures are taken dependent on a lawful system of the one-sided right of separation (divorce). Different examinations on a similar issue, yet this paper will investigate and issue with uncommon reference to family life and husband's brutality on different non-state thoughts.

Few endeavours condemn Domestic Violence are dependent on the non-state explanation of hurting companions as a right of Women. Pakistan is signatory, expand and stress upon equivalent privileges of people. In Pakistan Authoritative Framework of state stayed nonpartisan on the issue of Domestic Violence for quite a while and it was as of late condemned by the appropriation of different rules in both government and common levels (Ann, 2019). Pakistan is among the countries who are a participant to CEDAW and by ethic of this it is the commitment on the state to term aggressive behavior at home as encroachment of essential Human Rights and to establish and condemn it accordingly in its administrative system which is done up to more noteworthy level. Since turning out to be involved with CEDAW, Pakistan is attempting its level best to administer, teach and implement the laws identified to stop abusive behavior in home-country besides to different types of violence against ladies (Golubovskaya, 2019). Most noticeably awful recorded areas of Pakistan is Punjab of where beating spouses is intense according to the measurable information dependent on the investigation of Aurat Foundation during 2008-14 and the law to stop this viciousness was ordered in 2015 named as Punjab Protection of Women against Violence Act (Subramony, 2018). Before 2009, a similar issue was seen for legislation with the name of The Domestic Violence Act. From the Senate of Pakistan, this archive didn't get its agreement.

It worth referencing that law, after authorization, was broadly lectured by different philosophical pioneers expressing it 'un-Islamic' on the thought of spouses' 'right' torment wives (Kensbock S. J., 2013). In like manner, the Government of Sindh as of now presented their laws on a similar issue in 2013. Beforehand, the Protection of Women (Criminal Laws Amendment) Act changed different arrangements of Pakistan Penal Code (PPC) and Criminal Procedure Code (CrPC) making rape under Zina Offense by their living together accomplices (Henderson, 2007). Section 174 of $\mathrm{CrPC}$ was pointed toward checking settlement in-spired offenses of savagery. Numerous different measures were taken to ensure ladies at home-grown level, however, they fell prey to the male-centric direction of society (Berger, 2014). Although, the laws in Pakistan are available to deal with the issue of domestic violence. However, these laws have not been effective in dealing with the rise of domestic violence during the lockdown.

\section{THE CAUSES OF DOMESTIC VIOLENCE}

Poverty: Numerous analysts have discovered especially in Pakistan poverty is a contributing element of aggressive behavior at violence against ladies, where men are essential to bread workers. As it is relied upon by men to be all the more financially profitable and they need to give monetary help to their homes, if there should be an occurrence of inability to achieve those objectives they get baffled, and accordingly, ladies need to confront the maltreatment. A few examinations have demonstrated that segment factors, for example, age, number of living male kids, and more distant family habitation are related to the danger of abusive behavior at home because the bigger family prompts more desires from men (Bettiga, 2019). Clashes happen if family unit costs, kids training, different costs are not 
being paid by the accomplices. This likewise brings about savagery (both verbal and physical) against ladies.

Lack of women emancipation: In Pakistan ladies low strengthening and decreased independence is a contributing element for aggressive behavior and studies show that lower financial status, females' low schooling levels, and fewer opportunities for females are center components for low empowerment. Females in Pakistan are not viewed as able enough to take an interest in dynamic consequently, choices are taken by the male individuals in lady's life about issues, in any event, relating to her own life, for example, about females work, relationships, significant buys, number of youngsters, and even the choices concerning female's education (Deng, 2017). In Pakistan, the quantity of ladies in dynamic posts is hence; lower than in some other nation in the subcontinent (Friedman, 2016). Even if a lady needs to look for any clinical assistance to evade pregnancy because of her ailment, the choice is possibly taken by men, and on the off chance that she demands she is exposed to actual maltreatment. Furthermore, men additionally show and misuse the high position and force given to them by society as a top of the family. Going through the investigations of various societies in Pakistan, ladies are not considered for equivalent open doors in the creation of any choice not even at the hour of their relationships or some other choice identified with them.

Drug-addicts: Even though Pakistan is an Islamic nation, a lion's share of men are addicted to alcohol or other substance misuse and dependent private accomplices are generally observed as culprits for aggressive behavior at home against ladies. Alcohol usage is another setting off factor for violence, as it hinders critical capacities, diminishes the capacities to comprehend accepted practices and jobs. Utilization has additionally been noted as a factor in inciting forceful and savage male conduct towards ladies and kids. In any event, when the spouse calls attention to the perils of liquor to her accomplice, it frequently brings violence. The primary ramifications made by guys defending their rough conduct towards their ladies is that the religion gives them such freedom, which is a completely misrepresented conviction as cited by Qur'an. Indeed, their conduct paying little mind to which sex they have a place with is inappropriate regarding genuine Islamic lessons. Again separated from the way that liquor is disallowed in Islam as a result of the untoward impacts that it causes, it has been found as maltreatment, particularly against ladies in their home.

\section{ADOPTING ADVANCED STRATEGIES}

Online Monitoring System: During the Covid-19-lockdown, the countries around the world have adopted online emergency services for making the response against domestic violence more vigilant. The governments are using mobile phone applications and internet websites to start SOS calls to make the complaint system effective in the days of lockdown. The government hotlines are connected to the online complaint system for synergising the response system. The online report system, in the times of COVID-19, may look costly, however, it can effectively contribute to solving the issue of domestic violence. The digital monitoring of domestic violence cases can effectively make the response system vigilant, easier, and discrete. To deal with domestic violence, Pakistan has started the idea of digital vigilance, however, there is a need to connect the idea with the overall administrative framework dealing with the issue of domestic violence.

Governmental Vigilance toward Protecting Vulnerable Groups: A methodology is expected to recognize whether the vulnerable are in like manner experiencing a further degree of violence. One such organization that is particularly vulnerable is the transient organization (Lim, 2012). Because of lockdown, it may not be conceivable for these organizations to re-appearance in their nearby spots. Again, as openings for work become confined, they will undoubtedly experience exploitation and may not state the issue. People moreover experience various sorts of division, including social isolation, disgrace, etc. Besides, further loss masses who are extra defenseless against Covid-19 are people with a greater danger of genuine infection, more settled adults, immune-deficient individuals, liver illnesses, HIV, etc. Subsequently, through Covid-19, such organizations need extraordinary action. Such a plan is counter harsh prototypical, that trains feeble organizations about basic organizations and assets expected to live securely away from local violence (Wu, 2018). These practices diminish the power and likewise decidedly influence the probability of announcing. Policymakers put extra consideration on weak gathering either by making mindfulness or by separating and giving consideration. For casualties that have a place with weak gatherings, advising their status forthright to 
specialist co-ops will assist them with getting organized administrations (Menefee, 2016). For specialist organizations, considering legitimate concern for weak gatherings, the production of unique reaction gathering, an exceptional hotline number, and an uncommon assistance system will assist with bending the negative effects.

Community's Role: Since the capacity of helplines just as office-based guides and different associations to help the overcomer of misuse would be exceptionally restricted under the current limitations, one would need to investigate approaches to look for network uphold: it is the network which stays best prepared to help an overcomer of violence. Working together with the neighborhood network-based associations is probably going to arise as a compelling enthusiastic wellbeing net. The people group can offer the most open help to survivors in the current occasions, as they are frequently incapable to head out to the medical clinic or police headquarters to look for help or call up a helpline (Xie, 2020). Associations and helplines need to team up with network pioneers, Panchayat individuals, and heads of different grassroots associations to co-plan techniques to manage domestic violence cases in their particular areas.

Awareness drives and active messaging: This is an easy methodology: spreading mindfulness that violence isn't defended whatever the objective and ought not to go on without serious consequences at any check, and that help is accessible. It ought to get the amplest conceivable exposure. This is possible in India given the wide inclusion cell phones and TVs have - writings and recordings are circled across social average stages, for example, WhatsApp in enormous volumes: flowing such mindfulness missions and recordings is anything but a significant test. A few NGOs could be engaged with growing such substance. Associations, for example, Aurat Foundation and White Ribbon, which have been taking a shot at fundamentally the same as issues for more than quite a long while, could be engaged with outlining the subtleties. Quantities of NGOs who can be drawn closer for help and backing during seasons of domestic violence are circling on the web, yet not being supported by the public authority (Yuan, 2020). For the public authority to effectively advertise these contacts would give out a far more grounded message.

\section{CONCLUSION}

The paper has examined the issue of domestic violence during the days of the COVID-19 lockdown. The paper finds the response against the surge in domestic violence cases requires the state to do more for protecting the vulnerable women forced to stay at home due to lockdown. The causes for the violence remain multifarious such as multiplied poverty, lower status of women in traditional socioreligious society, and drug addiction issues. The paper suggests that the gravity of the issue of domestic violence needs an effective response from the government by using digital vigilance and reporting system, prioritising the administrative response to protect women in the lockdown, and educating the communities to play their role in protecting women. The COVID-19 pandemic has given rise to pandemic-plus in the shape of domestic violence against women under the lockdown. One must be an optimist to hope for the elimination of COVID-19 by an effective vaccine, however, the pandemic-plus requires the government of Pakistan to do more and do long-term.

\section{REFERENCES}

Ann, S. A. (2019). Motivating senior employees in the hospitality industry. International Journal of Contemporary Hospitality Management.

Basch, C. M.A. (2018). Health information seeking behavior among college students. Journal of Community Health.

Berger, J. (2014). Word of mouth and interpersonal communication: a review and directions for future research. Journal of Consumer Psychology.

Bettiga, D. L. (2019). Individuals' adoption of smart technologies for preventive health care: a structural equation modeling approach. Health Care Management Science.

Bradbury-Jones, C. a. (2020). The pandemic paradox: the consequences of COVID-19 on domestic violence. Journal of Clinical Nursing.

Campbell, A. (2020). An increasing risk of family violence during the Covid-19 pandemic: strengthening community collaborations to save lives. Forensic Science International: Reports, 100089. 
Deng, Z. a. (2017). Understanding consumer health information-seeking behavior from the perspective of the risk perception attitude framework and social support in mobile social media websites. International Journal of Medical Informatics.

Friedman, D. G. (2016). Increasing community awareness about Alzheimer's disease in Puerto Rico through coffee shop education and social media. Journal of Community Health.

Golubovskaya, M. S. (2019). Recalibrating talent management for hospitality: a youth development perspective. International Journal of Contemporary Hospitality Management.

Goyal, M. (2020). Covid-19: how the deadly virus hints at a looming financial crisis. The Economic times.

Henderson. (2007). Corporate social responsibility and tourism: hotel companies in Phuket, Thailand, after the Indian ocean tsunami. International Journal of Hospitality Management.

Jackson, D. e. (2020). Life in the pandemic: some reflections on nursing in the context of COVID-19. Journal of Clinical Nursing.

Jenkins, A. (2018). Ageism and age discrimination in hospitality employment: issues, challenges and remedies, in Burke R. and Hughes J.C. (Eds): Handbook of Human Resource Management in the Tourism and Hospitality Industries, Edward Elgar Publishing.

Kensbock, S. J. (2013). The lowest rung': women room attendants' perceptions of five star hotels' operational hierarchies. International Journal of Hospitality Management.

Lim, S. a. (2012). The role of trust in the use of health info mediaries among university students. Informatics for Health \& Social Care.

Logar, R. a. (2017). Emergency Barring Orders in Situations of Domestic Violence. Article 52 of the Istanbul Convention, Council of Europe.

Lowery, C. B. (2019). Antecedents of union support in the United Stateshospitality industry. Journal of Human Resources in Hospitality and Tourism.

Menefee, H. T. (2016). Mechanisms of communicating health information through Facebook: implications for consumer health information technology design. Journal of Medical Internet Research.

Schumacher, J. C. (2010). Intimate partner violence and Hurricane Katrina: predictors and associated mental health outcomes. Violence and Victims.

Smith, S. F. (2014). Intimate partner homicide and corollary victims in 16 states: national violent death reporting system, 2003-2009. American Journal of Public Health.

Straus, M. a. (1992). Verbal/symbolic aggression in couples: incidence rates and relationships to personal characteristics. Journal of Marriage and the Family.

Subramony, M. S. (2018). Service work in 2050: toward a work ecosystems perspective. Journal of Service Management.

Wu, T. D. (2018). Seeking and using intention of health information from doctors in social media: the effect of doctor-consumer interaction. International Journal of Medical Informatics.

Xie, B. H. (2020). Global health crises are also information crises: a call to action. Association for Information Science and Technology.

Yuan, C. N. (2020). The influence of peer beliefs on nurses' use of new health information technology: a social network analysis. Social Science \& Medicine. 